\title{
CuANDO El OPIO SE REBEla: LA CONFRATERNIDAD CRISTIANA DE IGLESIAS (EVANGÉliCAS) EN SU CRÍTICA A LA DICTADURA MILITAR Y SU PROYECTO DE SOCIEDAD (1981-1989)*
}

\author{
"When Opium Rebels: the Confraternidad Cristiana de Iglesias \\ (Evangelical) as a critic of the Military Dictatorship and \\ its Project of Society (1981-1989)"
}

\section{MIGUEL ÁNGEL MANSILLA}

INTE-Universidad Arturo Prat

\section{JUAN SEPÚLVEDA}

SEPADE

\section{LUIS ORELLANA}

Universidad de Santiago de Chile

\begin{abstract}
RESUMEN
Este artículo hace un análisis de la Confraternidad Cristianas de Iglesias que nació en 1981, como una minoría religiosa evangélica y pentecostal activa y liberacionista, que se desprivatiza para insertarse en el mundo público con el objetivo de protestar contra las condiciones políticas, sociales y económicas; luchar por la democracia; y asume una postura política pacífica y no violenta, frente a la dictadura. Para ello se hace un análisis de cuatro declaraciones públicas realizadas entre 1984 a 1988 que fueron publicadas en la Revista Evangelio y Sociedad. El propósito de este artículo es debatir y rebatir las investigaciones anteriores respecto del movimiento evangélico chileno, concebidos como sustentadores ideológico-religiosos de la dictadura militar.
\end{abstract}

Palabras clave: Evangélicos, minoría activa, cristianismo liberacionista.

\begin{abstract}
This article is an analysis of the Confraternidad Cristiana de Iglesias (Christian Fellowship of Churches), which was founded in 1981 as an evangelical and Pentecostal religious minority active and liberationist, which deprivatize in entering the public world and protest against the political, social and economic; fight for democracy, and assumes a political stance peaceful and non-violent, against the dictatorship. This is an analysis of four public statements made between 1984-1988 that were published in the Magazine Evangelio y Sociedad. The purpose of this article is to discuss and refute previous research on the Chilean evangelical movement conceived as ideological-religious supporters of the military dictatorship.
\end{abstract}

Key words: Protestantism, active minority, liberationist christianity. 


\section{INTRODUCCIÓN}

En la literatura académica se suele afirmar que todos los evangélicos chilenos brindaron su apoyo a la dictadura militar (Lagos, 1988; Stoll, 1990; Bastian, 1994; Löwy, 1999). Esta idea se originó en la Declaración Pública que firmó un grupo de 32 dirigentes evangélicos en un acto de apoyo convocado por el Consejo de Pastores (CP) el 13 de diciembre de 1974, pero cuya representatividad se suele extender a todos los evangélicos, ganando así "el mito de los evangélicos como conservadores, anticatólicos y antimarxistas" (Fediakova, 2004: 261). Por ejemplo, Bastian menciona que fueron 70 los líderes evangélicos firmantes de la referida declaración, citando a El Mercurio del 19 de diciembre de 1974 (1994: 269). Sin embargo, hay testimonios que permiten poner en duda la espontaneidad con que se produjo este acto de apoyo al régimen militar, ya que la convocatoria fue acompañada por el anuncio de que las denominaciones que no asistieran podrían perder su personalidad jurídica (Palma, 1988: 101).

También "la opinión pública... mantenía la idea de que los evangélicos eran adictos al gobierno militar" (Análisis, 1986: 17). ¿Cuáles fueron las posibles causas de esta idea tan generalizada? Fundamentalmente se debe a que la dictadura militar supo "utilizar muy bien el apoyo prestado por algunos sectores protestantes, haciendo resaltar el hecho por los medios de comunicación" (Análisis, 1986: 17). Además, por "la posición del CP, por su acceso expedito a una prensa absolutamente controlada por el gobierno, logra imponerse casi sin contrapeso como la posición de todos los evangélicos chilenos" (Sepúlveda, 1986:5), a pesar de la opinión disidente de la Asociación de Iglesias Evangélicas de Chile (AIECH). Sin embargo, más que oponerse a la dictadura militar, la AIECH cuestionó al CP por pretender representar a todas las iglesias evangélicas y por traicionar su independencia política, defendiendo implícitamente el carácter "privado" de la religión (Casanova, 1994).

Contrariamente, las posiciones adoptadas tanto por el CP desde 1974, como por la CCI desde 1984, representan una novedosa irrupción de dirigentes evangélicos en el espacio público, transformándose en casos de lo que Casanova describe como la "desprivatización" de la religión en el mundo moderno (Casanova, 1994). En el primer caso, se trata de una intervención en lo público que intenta emular la relación de legitimación mutua entre iglesia católica y Estado, un "anacronismo residual" de la situación previa a la separación entre ambos. El segundo caso, en cambio, al defender precisamente el Estado de Derecho, y en particular los derechos humanos, representa una forma de "desprivatización" de la religión compatible con la modernidad (Casanova, 1994: 218-224).

Sobre el rol público de la CCI como organización religiosa durante la dictadura militar hay escasas referencias en la literatura académica. La mencionan algunos estudios que tratan acerca de defensa de los derechos humanos, ecumenismo y compromiso social (Ossa, 1999; Harper, 2007; Lagos, 1991; Sepúlveda, 2003; Fediakova, 2004), pero no existen investigaciones que analicen los fundamentos sociopolíticos de la CCI en su inserción pública. Es notable que la CCI ni siquiera sea mencionada por Michael Löwy (1999), quien alude a distintos grupos católicos y evangélicos revolucionarios y disidentes de las dictaduras militares de América Latina. 
Los cientistas sociales que han estudiado la relación entre evangélicos y política en Chile (d’Epinay, 1968; Tennekes, 1985; Lagos, 1978, 1988; Stoll, 1990; Beyer y Fontaine, 1991; Bastian, 1994; Löwy, 1999) lo han hecho considerándolos como minorías funcionales resignadas al poder político de turno. En términos metodológicos, no se han analizado las revistas evangélicas, algunas de las cuales se publicaron a contar de 1910. Esto no ocurre por desconocimiento, sino más bien por desconfianza ante las fuentes evangélicas. En cambio, nosotros haremos un amplio uso de la revista Evangelio y Sociedad (EyS), que fue publicada por SEPADE ${ }^{1}$ entre 1985 y 1995, completando un total de 21 números. EyS informó sobre la totalidad de las cartas y declaraciones públicas realizadas por la CCI, que fueron 10 en total. Aquí centraremos el análisis en cuatro declaraciones públicas que, a nuestro juicio, representan el mensaje más contestatario de los evangélicos a la dictadura militar en Chile:

- Carta a la Opinión Pública Nacional (COPPN, 1984);

- Declaración Pública en conmemoración al Centenario de los sucesos de Chicago (DPCCH, 1986);

- Carta a Abierta al Presidente Pinochet (CAP, 1986);

- Carta al Pueblo Evangélico y a la Opinión Pública frente al Plebiscito (CPEOPP, 1988).

Frente a tales pronunciamientos, cabe preguntarse por los vínculos e influencias nacionales e internacionales que permitieron a la CCI resistir, protestar y rebelarse contra la dictadura. ¿Cuáles fueron los presupuestos ideológicos que sustentaron y orientaron la crítica de esta organización evangélica a la dictadura militar y su proyecto de sociedad? Es decir, no basta considerar solo principios teológicos, como lo destaca Humberto Lagos (1991). Se necesitan además fundamentos políticos que se desprenden de estos fundamentos teológicos para que sea verdaderamente una protesta política y económica, y no meramente una protesta simbólica.

\section{LA CCI: INFLUENCIAS Y VÍNCULOS NACIONALES E INTERNACIONALES}

La diversidad institucional de las iglesias evangélicas no es una novedad, puesto que las ha caracterizado desde antes que se implantaran en Chile. Sin embargo, su condición minoritaria las impulsó a actuar unitariamente en sus relaciones con la sociedad y el Estado. Por otra parte, el movimiento de unidad evangélica en América Latina, como expresión del emergente movimiento ecuménico mundial, tuvo un impacto temprano en el país. Ya en 1941 nació el "Concilio Evangélico de Chile" (CEC), con participación de iglesias de todo el espectro confesional, incluso pentecostales. Así, a mediados del siglo XX podía hablarse del "pueblo evangélico chileno" como un actor social bastante unitario (Sepúlveda, 1999: 117-126).

1 El "Servicio Evangélico para el Desarrollo" (SEPADE) funcionó durante la dictadura como un Centro de Educación y Servicio de la Misión "Iglesia Pentecostal”, constituyéndose como una corporación autónoma en 1995. 
Esto cambió en la década de 1960, cuando comenzó a sentirse en Chile la creciente polarización teológica-ideológica del protestantismo mundial entre la tendencia fundamentalista y la ecuménica, en el contexto de la "Guerra Fría". Chile durante la Unidad Popular (1970-1973) fue un campo fértil para la irradiación de esta polarización, generando las condiciones para las reacciones opuestas que surgirían más tarde frente a la dictadura (Sepúlveda, 1999: 134-139). Si bien en el Acto Ecuménico de Oración por Chile realizado en la Plaza de la Constitución apenas dos días antes del golpe (Lagos, 1988: 61); en la primera declaración ecuménica ante las nuevas autoridades militares, tres días después del golpe (Maldonado, 2012: 39); y en la creación del "Comité de Cooperación para la Paz" (COPACHI) el 9 de octubre de 1973 (Valech, 1991: 43), se vio todavía actuando juntos a dirigentes de la "Iglesia Metodista Pentecostal" con el obispo luterano Helmut Frenz. El mencionado acto de diciembre de 1974 evidenció la escisión del mundo evangélico en su respuesta al nuevo escenario político. El recién creado CP se alineará abiertamente a agrupaciones internacionales de orientación fundamentalista, de preferencia con la Confraternidad Evangélica Latinoamericana, CONELA (Palma, 1988: 149), mientras la AIECH primero, y después la CCI, mantendrán los vínculos históricos con el movimiento ecuménico, base de su respaldo internacional.

Siendo la CCI parte de los "desposeídos del capital religioso" (Bourdieu, 2006: 42), probablemente no se hubiese convertido en la minoría liberacionista que llegó a ser, sin el apoyo de organizaciones internacionales como el Consejo Latinoamericano de Iglesias (CLAI), el Consejo Mundial de Iglesias (CMI), el Instituto Superior Evangélico de Estudios Teológicos (ISEDET) de Argentina, las Iglesias Reformadas de Holanda, la Misión de Basilea (Suiza), el Seminario Bíblico Latinoamericano y el Departamento Ecuménico de Investigaciones (DEI), ambos de Costa Rica, y un número significativos de entidades cooperantes de Europa, Norteamérica y Australia, con los que pudo desarrollar su "capital religioso" (Bourdieu, 2006: 62).

Este capital religioso del que era parte la CCI, "determinó su naturaleza, forma y estrategias para vincular trabajo religioso con el trabajo político" (Bourdieu, 2006: 62). En varias oportunidades el CMI, en coordinación con el CLAI, organizó delegaciones internacionales que visitaron a la CCI en señal de apoyo ecuménico (Sepúlveda, 1986; Harper, 2006). Este apoyo consistió, entre otras cosas, en difundir en el exterior las declaraciones públicas de la CCI. Estas denominaciones protestantes, en tanto que poseedoras del "capital de autoridad propiamente religiosa, les permite disponer y movilizar la fuerza material y simbólica" (Bourdieu, 2006: 62), resuelven compartir estos bienes religiosos y simbólicos con otros grupos de interés común.

Entre las instituciones nacionales que dieron sustento a la CCI, sobresalen a SEPADE y la Comunidad Teológica Evangélica de Chile (CTE). En conjunto impulsaron el Proyecto Unido de Educación Cristiana (PUEC) con el propósito de capacitar a jóvenes y mujeres evangélicas para actividades de educación cristiana, y producir material didáctico contextualizado para las comunidades evangélicas con una marcada connotación sociopolítica. De manera paralela, jóvenes y mujeres de las mismas iglesias asociadas a la CTE y la CCI pusieron en marcha referentes locales de la Unión Latinoamericana de Juventudes Ecuménicas (ULAJE) y de Mujeres Ecuménicas de Latinoamérica (MELA). 
PUEC, ULAJE y MELA constituyeron una plataforma de apoyo para las actividades convocadas por la CCI, lo que permite explicar el alto nivel de participación laica, en especial de mujeres y jóvenes. La "Guía Bíblica" publicada por PUEC, en continuidad de la "Guía Dominical", cuya publicación había iniciado SEPADE en 1981, aportó gran parte del material de estudio y reflexión bíblica que animó las liturgias y las "Jornadas de Oración por la Vida, la Paz y la Reconciliación", que desde 1986 convocó anualmente la CCI, culminando la primera de ellas con la firma de la Carta Abierta al General Pinochet (29 de agosto de 1986).

Entre los centros de estudios que nutrieron el pensamiento de la CCI, se destaca ISEDET. Allí se formaron o enseñaron algunas de las figuras más prominentes del ecumenismo latinoamericano y de la Teología de la Liberación (TL) en su versión protestante: José Míguez Bonino, Federico Pagura, Emilio Castro, entre otros, como también el destacado biblista católico Severino Croatto. Allí también se formaron profesores de la CTE como Manuel Hernández, Tomás Stevens, Dagoberto Ramírez y Juan Sepúlveda. A mediados de la década de 1980 la CTE llegó a tener un promedio superior a los cuatro mil estudiantes cada año en su programa de educación teológica por extensión. Un centenar de monitores y profesores, extendidos por casi todo el territorio nacional, eran los responsables de estimular la reflexión bíblico-teológica desde una óptica activa, liberadora y ecuménica. Las comunidades participantes de estos procesos eran mayoritariamente pentecostales, ubicadas generalmente en sectores populares. Así, las iglesias de la CCI pasaron de ser un grupo religioso puramente salvacionista-individualista (Weber, 2001; Bourdieu, 2006) a un grupo religioso de interés público (Casanova, 1994), transformando su capital simbólico (Weber, 2001) en capital político (Bourdieu, 2006).

En el ámbito del pensamiento y las ideas hubo docentes influyentes como los holandeses Hans de Wit, Tjeerd de Boer y Harry Smit, y el profesor norteamericano William Murdock. A lo anterior se sumaron las frecuentes visitas de destacados teólogos de la liberación y biblistas como José Míguez Bonino (ISEDET), Carmelo Álvarez (UBL), René Padilla (Argentina), Milton Schwantes (Universidad Metodista de Brasil) y el sacerdote católico Severino Croatto, entre otros.

Además de sus declaraciones públicas, la descripción de las actividades de la CCI incluye el acompañamiento pastoral, consistente en la presencia solidaria en funerales de víctimas de represión o en acciones de denuncia (huelgas de hambre y otras formas de protesta), apoyo moral-pastoral a organizaciones sociales, liturgias ecuménicas asociadas a diversos motivos y fechas (Sepúlveda, 1986). Varias de las iglesias miembros de la CCI participaban activamente de los programas impulsados por SEPADE (Centros de Recreación Infantil, Talleres de Mujeres, Centros de Abastecimiento Popular, etc.), involucrando a un activo voluntariado evangélico, especialmente de mujeres y jóvenes; y también de las actividades en el campo de los derechos humanos de FASIC (Fundación de Ayuda Social de las Iglesias Cristianas). Como consecuencia de las "transformaciones ideológicas religiosas" (Bourdieu, 2006: 55) que implicaban las actividades de estas iglesias y organizaciones ecuménicas, se produjeron amenazas y acciones intimidatorias por parte de los organismos de seguridad del régimen militar (Weingartner, 1988; Ossa, 1999). En este contexto, fue importante la solidaridad mutua con la Iglesia católica y en 
particular con la Vicaría de la Solidaridad, que heredó el apoyo de agencias protestantes de cooperación que antes había recibido el COPACHI. ${ }^{2}$

Tres de las declaraciones de la CCI que analizaremos respondieron a coyunturas particularmente conflictivas durante la dictadura militar. En 1983 se iniciaron las jornadas de protesta nacional (JPN) contra la dictadura mediante formas pacíficas de manifestación que involucraban no solamente a las organizaciones sociales, sino a amplios sectores de la población. Paralelamente se incrementaban acciones de grupos que validaban "todas las formas de lucha". En ese contexto se reactivan las acciones represivas por parte de las Fuerzas Armadas y de los organismos de seguridad y se hace público el proyecto de "ley antiterrorista", que buscaba proveer de un marco legal a esa nueva ola represiva. La COPPN (1984) fue la respuesta de la CCI a dicha coyuntura, representando su primer pronunciamiento teológico-pastoral sobre la situación global del país.

El carácter nacional y masivo de las JPN reveló la fuerza de la oposición a la dictadura, situación que empujó a los partidos políticos opositores a buscar formas de articulación política que fueran generando las condiciones para una eventual transición a la democracia. Así fue como se comenzó a visualizar 1986 como el "año decisivo". Sin embargo, la dictadura no parecía ceder ante las protestas y, contrariamente, concentraba todo su esfuerzo en su represión. La falta de señales de apertura fue preparando el terreno para que la propuesta de lucha armada tomara más fuerza, como se manifestó en la internación clandestina en Carrizal Bajo de armamento enviado desde Cuba. Fue en ese escenario que ocurrió uno de los casos de represión más violentos y emblemáticos, esto es, el caso de dos jóvenes quemados que costó la vida a Rodrigo Rojas y dejó gravemente quemada a Carmen Gloria Quintana. Este fue el hecho que motivó la CAP (1986), y la primera "Campaña de oración por la vida, la paz y la reconciliación", en cuyo marco fue redactada.

Por cierto que 1986 no fue el año decisivo, pero a pesar de la represión, la permanencia de las JPN contra la dictadura permitió que con la llegada de 1988 -año clave en el itinerario de la vuelta a la democracia trazado en la propia Constitución de 1980-, ocurriera en un clima muy poco favorable para la continuidad de un gobierno a esa altura completamente personalizado en la figura del general Pinochet. Mientras se reabren los Registros Electorales, la oposición enfrenta el debate entre los riesgos de embarcarse, en condiciones de desventaja, en la ruta trazada por la propia dictadura y la aparente inviabilidad de caminos alternativos. En ese escenario la CCI redactó y dio a conocer la CPEOPP (1988).

Si en periodos democráticos el 1 de Mayo, día de los trabajadores, ha sido una ocasión para que se expresen demandas sociales y económicas, con mayor razón lo fue durante la dictadura, particularmente en 1986, ocasión en que se conmemoró el centenario de los acontecimientos en Chicago que dieron origen al día de los trabajadores. Ese fue el motivo de la DPCCH (1986). 
No existe un estudio evaluativo del impacto del rol público que asumió la CCI en la década de 1980, pero hay un indicador sin duda relevante. En la víspera de la Jornada "Chile defiende la vida" realizada el 9 de agosto de 1984, la que contó con el respaldo público tanto de la Iglesia católica como de la CCI, el general Pinochet se refirió por primera vez a "las iglesias" (en plural, en lugar de hablar de "la Iglesia", como lo había hecho hasta entonces), lamentando su apoyo a la convocatoria. ${ }^{3}$ Esto significa que el propio general Pinochet acusó recibo del rol público de la CCI dos años antes que esta escriba una carta dirigida a él personalmente. Es importante como complemento mencionar que en la misma medida que la CCI fue conquistando espacio en los medios de comunicación, el CP fue reduciendo sus apariciones públicas, limitándolas a la transmisión oficial del "Tedeum Evangélico" cuyos discursos se fueron alejando de la incondicionalidad de los primeros años. Llegó incluso el momento en que sus principales dirigentes, en entrevista dada a El Mercurio (18 de octubre 1987, D 2-3), manifestaran que el CP, a diferencia de la CCI, no hacía declaraciones públicas. A estas alturas, entonces, mientras la CCI seguía embarcada en el proceso de "desprivatización" de la religión, el CP comenzaba a reivindicar su carácter "privado" (Casanova, 1994). Por tanto, podría sugerirse que el principal impacto del rol público de la CCI fue contribuir a la creciente carencia de legitimación religiosa de la dictadura.

Las declaraciones de la CCI tuvieron como eje central dos críticas: a) una al capitalismo neoliberal y b) otra dirigida a la dictadura militar.

\section{CRÍTICA AL CAPITALISMO NEOLIBERAL}

\section{Crítica al mercado}

La CCI comienza con críticas directas al modelo mercadocentrismo: "denunciamos el carácter injusto de un sistema económico que, en vez de fundarse en la satisfacción de las necesidades básicas de la población... privilegia a algunos grupos en perjuicio de la gran mayoría" (COPPN, 1984:1). La CCI estaba integrada tanto por líderes de la Iglesia Luterana y Metodista, es decir, minorías referenciales (Moscovici, 1981), como por líderes de Iglesias pentecostales (Misión Iglesia Pentecostal, Iglesia Pentecostal de Chile, Comunión de los Hermanos y Sendas Antiguas), las que dejan de actuar como minorías pasivas para constituirse en minorías activas. Gran parte de la membrecía de estas Iglesias corresponde a familias pobres, y estaban situadas en las comunas más necesitadas de Santiago, especialmente La Victoria y José María Caro, donde el porcentaje de desocupados estaba entre el 60 y 70\% de la población (Weingartner, 1988). Frente a ello no se podía guardar silencio, porque el aumento de la miseria, la pobreza y el desempleo eran innegables. Pero habían otros males "más condenables aún... el hecho de que derechos vitales como la salud, la educación, la vivienda y el trabajo son supeditados al 'libre juego' de las leyes del mercado" (COPPN, 1984: 1). Siendo los evangélicos vistos

3 Dato aportado por Juan Sepúlveda, a partir de las memorias de su participación en el proceso analizado. 
permanentemente como aliados del gobierno militar o apolíticos, críticas como estas eran consideradas como "el punto de vista de una minoría, o una mera opinión que refleja el punto de vista influidas por el error y la desviación" (Moscovici, 1981: 34).

Sin embargo, para el gobierno militar cualquier crítica o defensa de los desvalidos era considerada como una postura marxista. Tan asociado estaba el CMI a la izquierda, que algunos magazines norteamericanos no dudaron en llamarlo "el evangelio según Marx" (Sepúlveda, 1993: 15). En realidad lo que sucedía era que la miseria vivida, experimentada y observada por los evangélicos ya no era considerada como un fruto de la responsabilidad individual como tradicionalmente había ocurrido (Damboriena, 1957; Lalive d'Epinay, 1968; Tennekes, 1985). Ahora es concebida como una responsabilidad política. Pese que esta postura no era nueva, ya que hubo anteriormente voces disidentes desde el mundo evangélico, como el pastor Ríos, el pastor Víctor Mora, o el pastor metodista Antenor Vidal, quienes vincularon la pobreza a causas políticas y sociales. Pero estas solo fueron voces desérticas en medio de una sociedad que despreciaba a los evangélicos, voces que fueron demonizadas por los mismos evangélicos porque los vinculaban al socialismo.

Por tanto, la CCI podía recurrir a estas experiencias y transformarlas en "capital religioso para el ejercicio legítimo del poder religioso... para poder modificar las bases duraderas de las representaciones y prácticas de los laicos" (Bourdieu, 2006: 62), representaciones y prácticas que estaban asociados solo a una "religión del corazón" (Casanova, 1994: 54). Esto porque frente a la experiencia de miseria había que asumir una posición crítica. Al respecto señalan: "a diario, en nuestro trabajo pastoral, constatamos con dolor el gran deterioro de las condiciones de vida de los chilenos, cuyas expresiones escandalosas son: el hambre, desnutrición e indefensión de los niños" (COPPN, 1984: 1). Ante tales experiencias de miseria se justifica la "politización de la religión" (Casanova, 1994: 54), más bien la pregunta sería ¿por qué no se manifestó antes? Tal cuestionamiento se lo hicieron los Obispos de la Iglesia Metodista de Chile, Isaías Gutiérrez, y de la Iglesia Metodista Argentina, Federico Pagura, quienes señalaron: "si hay algo que lamentamos, es que hayamos guardado silencio por tanto tiempo" (Ossa, 1999: 38). Pero "la inconformidad manifiesta exponen a los individuos al insulto, el ostracismo e incluso a la persecución" (Moscovici, 1981: 70). Asimismo, se hace una defensa del derecho al trabajo frente a la explotación, el miedo y los sueldos de miseria de los obreros, como ocurrió con líderes metodistas y bautistas en Estados Unidos (Pope, 1942) o en Inglaterra (Hobsbawm, 1951).

Frente a la ausencia de estos derechos básicos, la CCI asignó legitimidad religiosa al derecho humano de protestar: "es propio del ser humano reaccionar cuando sus necesidades básicas están insatisfechas... la gente no tiene a quién recurrir, dónde reclamar, dónde participar para resolver sus problemas" (CAP, 1986: 2). Para la CCI la protesta era una reacción ante la insatisfacción de las necesidades básicas, mientras que para el gobierno militar era producto de la influencia que ejercía el marxismo internacional.

\section{El desamparo de los pobres}

En vista de la "desposesión y pauperización de los sectores populares" (Bourdieu, 2006: 44), los líderes de la CCI decidieron actuar públicamente, denunciando "la proliferación de 
males como el alcoholismo, la drogadicción, la prostitución y la delincuencia infantiles y juveniles" (COPPN, 1984: 1). Distintas organizaciones religiosas intentaban paliar estas miserias sociales en una doble estrategia: generando instancias alimentarias, recolección y entrega de indumentarias, creación y recreación de fuentes laborales de subsistencia, etc. Estos líderes religiosos defendieron la responsabilidad social de los cristianos como "algo querido por Dios, puesto que Él quiere que la vida se configure conforme a sus preceptos" (Weber, 2001: 104).

El Chile de la década de 1980 tuvo un retroceso de 50 años en materia social y política. Todo lo ganado desde el año 1938 se perdió. Épocas en que Chile era un país de muerte (Allende, 1939), miseria (Zañartu, 1938) y "de niños pobres" (Ahumada, 1958: 34), ahora, junto a la miseria y a la pobreza se suma la insensibilidad política del gobierno militar. Por ello se aconseja "...escuchar la voz de aquellos que han sido las víctimas permanentes y olvidadas de nuestra reciente historia nacional: los pobres de Chile" (COPPN, 1984: 1), siendo los evangélicos, específicamente, la religión de los pobres (Browning, et al., 1930: 30; Clark, 1956). No en vano el ser evangélico en Chile estuvo vinculado al ser pobre, marginal y analfabeto (Fediakova, 2004: 254). De esta manera "la CCI, sin tradición alguna, representaba simplemente la voz de un pueblo pobre y oprimido que, siendo creyente y religioso, no se deja dominar" (Ossa, 1999: 43).

Por una invitación de la CCI hacia fines de 1986, una delegación del CMI vino a Chile para expresar solidaridad con las iglesias chilenas. Esta delegación destacó "la sombría situación en lo referente a los derechos humanos y las incursiones y allanamiento brutales de las fuerzas de seguridad en los barrios pobres" (Harper, 2007: 74). Unos meses antes la CCI envío una Carta Abierta a Pinochet, donde es explícitamente crítica del actuar del gobierno. Ahora, la CCI se había transformado en una "minoría liberacionista" (Löwy, 1999), "una minoría activa" (Moscovici, 1981), respaldada internacionalmente con "la circulación del mensaje religioso, operado por especialistas" (Bourdieu; 2006: 56).

La CCI se identificó como una agrupación que es y está entre los pobres, lo que constituyó su capital religioso más valioso: "la mayoría de nuestras iglesias locales se encuentran ubicadas en los sectores más pobres de la ciudad. Por tal razón, en nuestra labor pastoral constatamos a diario el grave deterioro de las condiciones de vida de la población" (CAP, 1986: 1). Como la mayoría de las iglesias que integraban la CCI eran pentecostales (Harper, 2007), su cercanía a la pobreza no era fruto de una opción religiosa, sino un producto político. En estos contextos, es justificable que "la religión entre en la esfera pública, para proteger las libertades modernas y el derecho de la sociedad civil en contra de un Estado absolutista y autoritario" (Casanova, 1994: 57). Junto a la pobreza "las palabras hambre, cesantía, desnutrición, enfermedad, hacinamiento, deserción escolar, etc., son las que más verazmente describen la dramática situación de gran parte de la población chilena" (CAP, 1986: 1). Los evangélicos tuvieron el estereotipo de "beati pauperes (Damboriena, 1957:129). Sin embargo, ahora aparecen concibiendo la pobreza ya no como una virtud, sino una responsabilidad política. Por lo tanto, es posible que se le conciba como "un grupo de personas con un estatus poco elevado, que no tienen 
mucho que perder sino su propia marginalidad" (Moscovici, 1981: 73). Pero en realidad había mucho que perder: la personalidad jurídica de sus iglesias, quizás el mayor miedo del CP, asimismo de perder la vida. No obstante, lucharon ante "las consecuencias inhumanas de un sistema económico, que tiende a absolutizar la autorregulación del mercado" (Casanova, 1994: 58).

La CCI fue una minoría de minorías que se atrevió a criticar al general Pinochet y su proyecto neoliberal. Negándose de este modo a "limitarse solo al cuidado pastoral" (Casanova, 1994: 5), decide desprivatizarse y entrar en "una confrontación permanente de repolitización de las esferas religiosas y renormatización de las esferas económicas y políticas" (Casanova, 1994: 6). Su entrada en el espacio público ocurrió como una reacción a "la desesperación, frustración y... un conjunto de enfermedades sociales que están destruyendo la convivencia familiar y comunitaria: la drogadicción, la prostitución, la delincuencia, y lo que es aún más trágico, un notable incremento de suicidios" (CAP, 1986: 1).

La CCI se levantó como una voz de los desheredados, al decir que "la experiencia de los pobres es que han golpeado muchas puertas, pero todas permanecieron cerradas. $Y$ entonces recurren a las iglesias, que se han visto obligadas a desplegar múltiples esfuerzos para paliar la situación de miseria" (CAP, 1986: 2). Las distintas iglesias, tanto católicas como evangélicas, elaboraban diferentes estrategias para enfrentar la miseria durante las década de 1970 y 1980 pero no dieron abasto. "Para 1983 el 59\% de la población no alcanzaba a cubrir sus necesidades con el sueldo recibido producto de la desigualdad social. En 1983 el 20\% de la población solo recibía el 3,3\% de los ingresos del país, mientras que el 20\% de mayores ingresos recibían el 61\% de los ingresos" (Weingartner, 1988: 47). Para los integrantes del CCI esto resulta un escándalo, es decir, una inmoralidad, más aún, cuando se mostraba la supuesta riqueza del país en los medios de comunicación, acto que ofende y humilla a millones de pobres. Según Casanova, mediante este tipo a acciones, "la religión pública puede contribuir al fortalecimiento de la esfera pública de las sociedades civiles modernas" (1994: 8).

\section{La denigración del trabajo}

Se destaca que a "la experiencia de la pobreza se suma el desamparo, la soledad, la falta total de oportunidades de participar activamente en la solución de los propios problemas. Todo esfuerzo se torna inútil" (CAP, 1986: 2). Era una época en que "el $45 \%$ de la población nacional vivía en la pobreza y de ellos $25 \%$ vive en la indigencia" (Vuscovic, 1993: 16). El trabajo perdió su valor y el trabajador su dignidad, por las características de las políticas públicas para responder al desempleo (POJH y el PEM). La CCI hizo una apología del trabajo: "Dios mismo trabajó y descansó, e invitó a los seres humanos a trabajar junto a él para que la vida en esta tierra sea abundante, a gozar del descanso de la noche, y a disfrutar junto a su familia y los semejantes, de las bondades de la creación" (DPCCH, 1986: 34). Así la CCI, como minoría activa y liberacionista "hace una nueva lectura de la Biblia que da atención significativa a libros como el Éxodo" (Löwy, 1999: 51) y "el Génesis donde el Estado es representado como 
el poder faraónico que oprime, explota y expulsa a los campesinos, indígenas y obreros desde sus propiedades" (De Wit, 1988). Así, "una autoridad religiosa se dispone para combatir sobre el terreno propiamente simbólico las tentativas proféticas o heréticas de subversión del orden simbólico" (Bourdieu, 2006: 75). Desde esta relectura liberacionista, el trabajo es asociado inherentemente a la espiritualidad, el descanso, el comunitarismo, la utilidad, la creatividad, la libertad y la realización.

Desde la perspectiva de la CCI, el gobierno militar no solo pisoteó los derechos humanos con la tortura, desaparición de personas y el éxodo económico de miles de ciudadanos, sino que también con "la aplicación de un esquema de desarrollo económico centrado únicamente en las leyes del mercado, que ha significado una profunda postergación de los derechos de los trabajadores" (DPCCH, 1986: 35). El neoliberalismo desprestigia el trabajo y al trabajador. Los derechos laborales son reducidos a bienes y servicios expelidos en el mercado y el trabajador es una mercancía más. Luego está "la persistencia de un alto porcentaje de cesantía en la población... El aumento de la delincuencia, la prostitución, la drogadicción y el alcoholismo fueron una consecuencia directa de la cesantía" (DPCCH, 1986: 35). El trabajo se torna en una trampa neoliberal, al transformarlo en un bien escaso para tener una masa de trabajadores disponibles, pero también, "manteniendo la masa trabajadora en la pobreza" (Weber, 2001: 195).

Aunque el gobierno buscó subsanar esto con "los programas de emergencia como el PEM o el POJH... lejos de resolver el conjunto de problemas del cesante, los agrava... refuerza el sentimiento de dependencia y desvalorización personal" (DPCCH, 1986: 35). Esto implica la asignación a un trabajo sin sentido, una especie de mito de Sísifo. El PEM y el POJH transforman a los trabajadores tan pobres que ni siquiera les alcanza para llamarlos proletariados, sino que ahora son "pobretariados" (Löwy, 1999: 98). Además, estuvo el "gran deterioro de las condiciones de vida de quienes aún conservan su trabajo, lo que se expresó entre otras cosas en la nueva legislación de salud" (DPCCH, 1986: 35). Esto, sumado a "los tropiezos jurídicos o represivos que los trabajadores enfrentan en su tarea de organizarse y expresar sus justas demandas" (DPCCH, 1986: 35). No hay dónde requerir e incluso cualquier manifestación de reclamo es vista como terrorismo o postura marxista. Así se pierde "el sentido de solidaridad en las relaciones sociales, llevando a algunos grupos a realizar huelgas de hambre como medida extrema de protesta" (DPCCH, 1986: 35). Citando a Löwy, para la CCI como parte de una minoría activa y liberacionista, la idea de "pobre es un concepto que tiene connotaciones morales y bíblicas donde Cristo está reencarnado en los pobres crucificados de hoy" (1999: 98).

\section{CRÍTICA A LA DICTADURA}

La CCI formuló críticas y protestas contra la dictadura, algunas dirigidas directamente al general Pinochet. Lo notable es que con sus críticas y solicitudes la CCI no buscó beneficios corporativos para las iglesias evangélicas. Más bien defendió el bienestar de todos los chilenos y chilenas, especialmente los pobres y trabajadores. 


\section{Defensa de la democracia}

Se exige "que se abran las compuertas de la participación democrática. Es tiempo que a los chilenos se nos permita decidir sobre nosotros mismos y sobre el tipo de sociedad que anhelamos" (COPPN, 1984: 2). Con el uso de la metáfora pórtica se alude a una doble idea de apertura y trazado. Implícitamente se piensa en la dictadura como un sistema cerrado y la democracia como un sistema abierto. Pero la democracia requiere de un proceso de apertura, ya que la puerta fue cerrada violentamente. En segundo lugar, la puerta tiene una connotación de fundación, y al igual que en el pasado, la fundación de una ciudad implicaba un arado que trazaba el lugar de la puerta. En ese sentido, la democracia se entiende como un proceso de preparación y entrega, sin violencia, como fue el caso del golpe, sino por medios pacíficos. La exigencia y la búsqueda del retorno de la democracia se fundamenta en el principio de la "no violencia" (Boye, 1988: 134). Pero en una dictadura es imposible la paz, ya que su principio se funda en la violencia. Por ello la democracia se torna un imperativo moral, porque la paz solo es posible en "una sociedad democrática y pluralista en la que el pueblo, en sus diversas tradiciones de pensamiento y acción, puede elegir libre y directamente sus representantes" (COPPN, 1984: 2).

La CCI estaba innovando al incluir lo político en lo religioso. Esta innovación consistía en reflexionar acerca de la idea y práctica democrática desde la lectura eclesial de la Biblia. Una "democracia garantiza la vigencia y el respeto pleno de los derechos humanos" (COPPN, 1984: 1). Esta era otra idea innovadora de la CCI: el uso del concepto de los derechos humanos, odiado por la dictadura y visto con sospecha por otros evangélicos, lo que puede verse como una clara influencia del CMI. Así la CCI asume el perfil de las minorías activas cuyo rol es "ejercer influencia al oponerse a la conformidad y al consenso grupal, y que gracias a ello se hacen parte de la disidencia y la innovación" (Apodoka y Villarreal, 2008: 186).

Portar la democracia significa también abrir las puertas del retorno del exilio. Las lecturas bíblicas contextualizadas son promovidas por instituciones académicas como el ISEDET, el DEI y la CTE, inspiradas en experiencias veterotestamentarias como el exilio en Babilonia o Media-Persia o el retorno a Palestina y su relación con América Latina. En este contexto se destaca la urgencia de "la resolución definitiva del drama del exilio, que implica no solo la autorización del regreso, sino el gran desafío de la acogida y la reubicación (trabajo, salud, educación, previsión, vivienda) de las familias que retornan" (COPPN, 1984: 1). Se recurre a la metáfora del camino para hablar de la democratización como un proceso. La CCI como minoría activa y liberacionista dio a entender que "los sistemas sociales no son absolutos, sino resultado de confrontaciones y negociaciones de los diferentes actores sociales" (Apodoka y Villarreal, 2008).

Con la cercanía del plebiscito que la Constitución de 1980 establecía, en lugar de elecciones libres, como el primer paso en el itinerario hacia el retorno a la democracia, la CCI hizo una nueva declaración pública titulada: Carta al Pueblo Evangélico y a la Opinión Pública frente al Plebiscito (1988). Junto con reiterar varias críticas a la dictadura, mediante este pronunciamiento la CCI solicitó transparencia y celeridad en el proceso plebiscitario, y 
por otro lado instó a la población en general, y a los evangélicos en particular, a votar sin aceptar presiones, abogando por un proceso democrático libre y sin violencia. Al respecto dice: "es urgente reestablecer la democracia como el camino más confiable para resolver los grandes problemas de nuestro país, y superar el clima de tensión, violencia y temor que ha caracterizado el acontecer nacional en los últimos años" (CPEOPP, 1988: 1). Se destacan dos metáforas para resaltar la situación: la del camino y la climatológica. La primera para resaltar la idea de la democracia como un proceso que implica riesgo de desvío y confrontaciones, que pueden impedir la promoción democrática, pero también la idea del trazado y construcción de un periodo democrático. La idea de clima obedeció a una concepción naturalizada de la violencia que había construido el gobierno militar ante las demandas de participación del pueblo chileno.

\section{Defensa al derecho de protestar}

Se insta al "reconocimiento de la legitimidad y el derecho a disentir. Las protestas pacíficas que expresan el cansancio de un pueblo agobiado nos parecen legítimas, y corresponden a modalidades éticas cristianas de participación" (COPPN, 1984: 2). Aquí aparecen dos ideas fundamentales: a) la idea de "pueblo agobiado o pobre que sustituyen la idea de proletariado del marxismo" (Löwy, 1999: 103); b) y en segundo lugar le asigna a la protesta pacífica un fundamento inherentemente sagrado, como lo hiciera Paul Tillich para el caso del protestantismo (Tillich, 1965) o Sepúlveda para el caso del pentecostalismo (Sepúlveda, 2003). Mientras la CCI le asignó legitimidad teológica a las protestas populares, exige que "el gobierno militar, en vez de centrar su preocupación en las formas de reprimir o desvirtuar tales expresiones del sentir popular, debería detenerse a escuchar con respeto y buena voluntad las demandas expresadas" (COPPN, 1984: 2). La legitimación teológica de la protesta por parte de la CCI no justifica la violencia como recurso de resistencia popular y tampoco como represión estatal. "Como cristianos, condenamos el enaltecimiento de los medios violentos, tanto como fórmulas de mantención del poder, así como camino de acceso al poder" (COPPN, 1984: 3). Más bien se apeló a una filosofía de la no violencia (Boye, 1988), a una cultura de la paz promovida por el CLAI y teorizada por intelectuales en conceptos como cultura de la vida (Alves, 1989); educación para la paz (Altmann, 1989); o teología de la paz (Santa Ana, 1989).

Una de las principales estrategias de la acción no violenta "es la toma de conciencia de la situación que los oprime y el deber de luchar para terminar con ella" (Boye, 1988: 135). Por ello se instó a la resistencia y protesta pacífica. Las “JPN, los paros de actividades son legítimas... aunque las leyes vigentes proscriban estas manifestaciones, por cuanto no existen otros canales para una real y efectiva expresión de demandas de la población" (CAP, 1986:2). A las JPN se les asignó una legitimidad teológica y política. Dios mismo es presentado como un Dios que protesta mediante la voz de sus profetas. Se criticó notoriamente el uso ilegítimo y desproporcionado de la violencia por parte del Estado: "Declaramos que los frecuentes procesos en contra de los dirigentes son injustos. Ellos son personas que, arriesgando su propia seguridad, se ponen al servicio 
de sus organizaciones y de la comunidad nacional. No es justa una ley que considere a tales ciudadanos como delincuentes" (CAP, 1986: 3). No solo se persigue a los líderes políticos, sino también a los líderes religiosos (Weingartner, 1988; Sepúlveda, 1988; Ossa, 1999). Así, la CCI adquirió importancia "no solo por su carácter de minoría activa, sino también porque se inserta a un espacio conflictivo y peligroso" (Moscovici, 1981: 266).

Pero no se trata de protestar por protestar, sino para que Chile deje de ser un país pobre; para que se dignifique el trabajo y a los trabajadores, ya que las autoridades militares no lo harán. Por eso hacen "un urgente llamado para que escuchen las voces de nuestro pueblo, para construir un país donde la dignidad del trabajo y de los trabajadores sea el centro de todas las decisiones económicas y políticas" (CAP, 1986:3). La CCI recuerda que "las organizaciones sociales y sindicales de los trabajadores desde comienzo del siglo XX fueron fundamentales en la construcción de la democracia en Chile" (CAP, 1986: 3). Por lo tanto, no son marionetas del marxismo ni parte del complot de alguna mano invisible, sino memoria y patrimonio de la democracia chilena del siglo XX. Solo por medio de las protestas se ha logrado la democracia, y quienes han protestado históricamente son los sindicatos y trabajadores, los mismos de los cuales desconfía el gobierno militar.

\section{Crítica a la violencia}

Para la CCI la no violencia es principio y fundamento de la democracia. En cambio los medios que emplea la dictadura son violentos. Además "de la represión directa a las manifestaciones, hemos sido testigos directos o indirectos de múltiples formas de disuadir toda forma de participación por el recurso del miedo" (CAP, 1986: 3). La violencia del Estado dictatorial no solo se manifiesta en la represión callejera, sino también en el miedo y el terror llevado a los hogares, con los allanamientos y detenciones forzosas. En palabras de Boye, "la violencia está en el centro de toda dictadura" (1988: 108). Los allanamientos masivos a poblaciones "han significado graves vejaciones para los afectados, además de ser un atentado contra el derecho a la privacidad" (CAP, 1986: 1). Esto sucedía con mayor frecuencia en las poblaciones y barrios pobres: "Secuestran a personas, especialmente jóvenes, profiriéndoles amenazas y torturas físicas o psicológicas, o asaltan locales de instituciones solidarias eclesiales o civiles" (CAP, 1986: 3). Miedo, tortura y secuestro son las estrategias de las dictaduras dirigidas a los jóvenes e instituciones solidarias, para disuadir la reflexión, la crítica y la protesta. La Comisión Chilena de Derechos Humanos "informó que en los primeros treinta días del Estado de Sitio (septiembre de 1986) se registraron 6 asesinatos, 13 secuestros, 21 casos de torturas, 185 amenazas de muerte y 1.785 detenciones arbitrarias. El número total de detenciones había subido de 9.000 en 1985 a 31.084 en 1986" (Weingartner, 1988: 36).

Se responsabilizó al gobierno por el incremento de la violencia en las calles, al no dar respuestas a las demandas sociales y económicas básicas frente al hambre y el desempleo. "Es muy peligroso cuando un pueblo tiene la convicción de que no hay justicia, porque allí se alimenta la tentación de asumir la justicia en las propias manos" (CAP, 1986: 3). Es la idea de que la "violencia engendra nueva violencia" (Weber, 2001: 537). Como toda dictadura acusa a la disidencia de ser parte de un complot internacional, la CCI denunció 
que "con demasiada rapidez se califica a quienes hacen críticas dentro o fuera del país, como enemigos de la patria o títeres del comunismo internacional" (CAP, 1986: 3). Se intentó deslegitimar a la CCI a través de su vínculo con CMI, al que acusan de ser "ciego del ojo izquierdo" (Brakemeier, 2010: 5), muy crítico con los gobiernos derechistas, pero complaciente con los gobiernos de izquierda.

La violencia del gobierno engendra violencia, porque "el gran descontento popular... [y la] falta de voluntad política del gobierno para tomar seriamente en cuenta este descontento, ha originado un verdadero clima de guerra" (CAP, 1986:3). No se evidencia ninguna actitud de reflexión o de autocrítica, por el contrario, siempre se culpó a los marxistas. "Esto ha ido provocando en muchas personas, especialmente en jóvenes cuya vida no tiene ningún futuro en las actuales condiciones, la convicción de que solo se pueden cambiar las cosas recurriendo también a la violencia" (CAP, 1986: 3). Se criticó la violencia del Estado porque engendra violencia, pero también se justifica "el derecho a la resistencia activa contra la violencia secular" (Weber, 2001: 540). Se defiende incluso el carácter pacífico del pueblo chileno, al afirmar que "ama la paz y no quiere la guerra. Ya son demasiadas las heridas acumuladas como para profundizarlas" (CAP, 1986: 5). Pero el pueblo también busca la "sanidad social" y la única forma de lograrlo es a través de la democracia. Por tanto, siendo que "el espiral de violencia no se puede detener con más violencia" (CAP, 1986: 3), entonces se hace necesario que los militares entreguen el poder político y den lugar al retorno de la democracia. De esta manera la, CCI "en su inserción pública no pone en peligro las libertades individuales" (Casanova, 1994: 215).

La CCI le asignó un fundamento sagrado al llamado a la democratización. Por lo tanto, "en nombre del Dios dador y sostenedor de la vida, proclamamos la urgente necesidad de restablecer una sociedad participativa, pluralista y democrática, basada en el respeto a los derechos humanos" (CAP, 1986: 3). La exigencia es que se inicie de inmediato "un proceso de transición democrática que el propio pueblo de Chile determine a través de sus variadas organizaciones" (CAP, 1986: 3). Para el pueblo, el fundamento de una sociedad es la participación, en cambio para los militares es el orden.

\section{Crítica a las Fuerzas Armadas}

Se le señala a los militares que el pueblo chileno no los quiere en el gobierno y exigen el retorno de la democracia: "las instituciones armadas... se están haciendo responsables del creciente clima de guerra que tendrá imprevisibles consecuencias para el país, y acreedores del juicio de Dios por la sangre derramada" (CAP, 1986: 3). Esta fue una época muy intensa de la CCI, junto a otras instituciones como el SEPADE, donde se buscó concientizar a los feligreses para luchar por el retorno de la democracia. En el año del Plebiscito, SEPADE elaboró la cartilla Orientaciones bíblicas para la participación ciudadana (1988), con las unidades: a) "La participación ciudadana de los cristianos: ¿Un deber o algo prohibido?"; b) “QQué nos enseña la Biblia sobre una sociedad participativa?"; c) "Una advertencia sobre el peligro de la concentración del poder"; d) "La responsabilidad de elegir"; d) "Y después que...?"; todo esto para promover la reflexión en las iglesias locales, contrarrestar el temor y estimular la inscripción en los registros electorales. 
La CCI destacó que en el país existe un clima adverso, fomentado por el mismo gobierno con su propuesta de prolongar su gestión gubernamental: "el plebiscito exacerba el clima confrontacional que vive el país. Además involucra directamente a las FF.AA., que tradicionalmente fueron garantes imparciales de los procesos eleccionarios y lucha política" (CPEOPP, 1988: 2). Otro elemento que se destaca es la politización de las Fuerzas Armadas, las que se han ideologizado y se han constituido en un cuasipartido derechista. Por esta razón, declaró su preferencia por un proceso de elecciones libres.

Una vez defendida la democracia como el único y mejor gobierno, se procede a exigir condiciones de transparencia: "el gobierno debe dar a conocer una fecha cierta para su realización, con la máxima antelación posible a la publicación del decreto respectivo. La incertidumbre respecto de la fecha produce desconfianza y confusión a la ciudadanía" (CPEOPP, 1988: 2). Para evitar la posterior violencia de resistencia, se insta a anunciar los mecanismos para promover los derechos democráticos exigidos por la ciudadanía. Es así como en esta lucha por el retorno de la democracia que la CCI fue considerada como un interlocutor religioso-político válido hasta finales de 1990.

\section{Defensa de la ciudadanía}

Una y otra vez se recurre a legitimar la participación democrática desde fundamentos metasociales: "desde nuestra perspectiva cristiana, reconocer el derecho a la ciudadanía es lo menos que puede hacerse para respetar la dignidad de cada ser humano creado a imagen y semejanza de Dios" (CPEOPP, 1988: 2). En este sentido la CCI como grupo religioso "está predispuesta a asumir una función ideológica, práctica y política de legitimación" (Bourdieu, 2006: 50), como es el caso de la resistencia activa que conlleva a la democratización. Se destacan los fundamentos pastorales para resaltar valores que solo se pueden dar en y desde la democracia: "desde nuestra perspectiva pastoral, estas condiciones brotan en primer lugar de valores centrales de las Sagradas Escrituras: la equidad... igualdad entre seres humanos... la verdad como fuente de la libertad... la justicia como fuente de paz...; y el derecho a la seguridad e integridad de la persona" (CPEOPP, 1988: 2). Se insistió en esta defensa metasocial y trascendental de la democracia aun cuando "los evangélicos eran presionados por el gobierno militar, sobre todo en Concepción" (Ossa, 1999: 109).

Luego los pastores vinculan su rol pastoral con el servicio público y se ofrecen a participar como garantes y observadores del proceso eleccionario: esto significó una transformación simbólica por parte de la CCI. Pero como "no hay revolución simbólica que no suponga revolución política" (Bourdieu, 2006: 83), entonces la CCI no solo se hace parte de la lucha por la concientización democrática, sino también parte del proceso: "Como pastores, inspirados en nuestra vocación de servicio, manifestamos desde ya nuestra disposición de actuar como testigos morales de todo proceso" (CPEOPP, 1988: 2). El ofrecimiento por parte de la CCI como observador y garante del plebiscito "será aceptado por la oposición y el comando por el NO. Así la CCI, la Iglesia católica y la masonería quedaron como instancias observadoras del proceso" (Ossa, 1999: 109). Parafraseando a Bourdieu podemos decir que son las situaciones 
extraordinarias las que transforman los grupos en extraordinarios (Bourdieu, 2006: 80). Se insta a la conciencia y participación ciudadana de los evangélicos: “ ...todos los seres humanos y especialmente los creyentes, están llamados a participar responsablemente en la construcción y perfeccionamiento de tal ordenamiento social. Es pues, urgente que quienes no lo hayan hecho se inscriban prontamente en los registros electorales a fin de estar habilitados para ejercer su responsabilidad ciudadana" (CPEOPP, 1988: 2). Así, las iglesias de la CCI pasan de una "función mistificadora del desplazamiento de los conflictos políticos" (Bourdieu, 2006: 51) a una responsabilidad política actualizada. También se hizo un llamado a la defensa de la libertad de conciencia política sin presiones políticas o pastorales: "hacemos un llamado a rechazar y denunciar todo tipo de presión tendiente a condicionar su voto. Como evangélicos, somos fervientes defensores del derecho a la libertad de conciencia. Cada persona debe reflexionar responsablemente y votar por razón de su conciencia, como hombres libres" (CPEOPP, 1988: 1). De esta manera la "desprivatización es la reubicación de la religión en la esfera pública de la sociedad civil, es una etapa de transición que está condicionada por el propio éxito del movimiento" (Casanova, 1994: 222). Pero una vez que el movimiento religioso ha tenido éxito con la consolidación de un régimen democrático, se autorretira hacia su espacio privado, pero no por su propia voluntad, sino porque en las condiciones democráticas la sociedad ya no los necesita.

\section{CONCLUSIÓN}

En este artículo tratamos respecto del rol de la Confraternidad Cristiana de Iglesias (CCI) durante la dictadura militar de Augusto Pinochet. Esta asociación de iglesias evangélicas publicó 10 cartas abiertas entre 1983 y 1988. Aquí centramos el análisis en cuatro de ellas que, a nuestro juicio, representan el mensaje más contestatario de dicha asociación durante la dictadura. Resaltamos las influencias y vínculos nacionales e internacionales que tuvo aquella asociación para realizar tales declaraciones y asumir una posición crítica al gobierno militar, tan peligroso para la época. Luego destacamos dos ejes centrales de la crítica realizada al capitalismo neoliberal que incluyó el mercadocentrismo; el desamparo de los pobres; y la denigración del trabajo. Por último, en su crítica a la dictadura reprochó la violencia ejercida por las Fuerzas Armadas e hizo una defensa de la democracia, al derecho de protestar y al ejercicio de la ciudadanía.

\section{REFERENCIAS}

Ahumada, Jorge. 1958. En vez de la Miseria. Santiago: Pacífico.

Allende, Salvador. 1939. La realidad médico-social chilena. Ministerio de Salubridad, Previsión y Asistencia Social. Santiago: Lathrop.

Alves, Rubén. 1989. "Cultura de la Vida”. En Hacia una Cultura de la Paz, Simón Espinosa (Compilador). Venezuela: Nueva Sociedad.

Altmann, Walter. 1989. “Educación para la Paz". En Hacia una Cultura de la Paz, Simón Espinosa (Compilador). Venezuela: Nueva Sociedad. 
Apodoka, Eduardo y Villarreal, Mikel. 2008. El poder en busca de autoridad: las dinámicas psicosociales de la legitimación. España, Alicante: Club Universitario.

Assmann, Hugo; Franz, Hinkelhammert; Jorge, Pixley; Pablo, Richard y Jon Sobrino. 1980. La lucha de dioses. Los ídolos de la opresión y la búsqueda del dios libertador. San José, Costa Rica: DEI.

Bastian, Jean. 1994. Protestantismo y modernidad latinoamericana. Historia de unas minorías religiosas activas en América Latina. México: FCE.

Beyer, Harald y Fontaine, Arturo. 1991. "Retrato del movimiento evangélico a la luz de las encuestas de opinión". Estudios Públicos, $\mathrm{N}^{\circ} 44$.

Boye, Otto. 1988. La No Violencia Activa. Camino para conquistar la Democracia. Santiago: Aconcagua.

Bourdieu, Pierre. 2006. "Génesis y estructura del campo religioso". Relaciones 108 (27): 28-83.

Brakemeier, Gottfried. 2010. "Curso de Ecumenismo. Breve Historia del Consejo Mundial de Iglesias". Consultado el 15 de abril del 2013, (http:/ / www.claiweb.org/cursos\%20online/Ecumenismo/v\%20 CMI.pdf )

Browning, W; Ritchie, J; y Grubb, K. 1930. The West Coast Republics of South America. Chile, Peru and Bolivia. Londres: World Dominion Press.

Casanova, José. 1994 Public Religions in the Modern World. Chicago/London: University of Chicago Press.

Clark, Elmer. 1956. The Small Sects in America. Little Known Religious Groups History. New York.

Damboriena, Prudencio. 1957. "El Protestantismo en Chile". Mensaje 6.

De Wit, Hans. 1988. He visto la humillación de mi pueblo. Relecturas del Génesis desde América Latina. Santiago: Amerinda.

Fediakova, Eugenia. 2004. "Somos parte de esta sociedad. Evangélicos y Política en el Chile postautoritario". Revista Política 43 (Primavera).

Fontaine, Juan. 1987. “La economía chilena en los años ochenta: ajuste y recuperación”. Series de Estudios Económicos 34. Banco Central de Chile.

Harper, Charles. 2007. El acompañamiento. Acción ecuménica por los derechos Humanos en América Latina 1970-1990. Uruguay: Trilce.

Hobsbawn, Eric. 1951/2003. Rebeldes primitivos. Estudios sobre las formas arcaicas de los movimientos sociales en los siglos XIX y XX. Barcelona: Crítica.

Lagos, Humberto. 1978. La libertad religiosa en Chile, los evangélicos y el gobierno militar. Tomo 1. Investigación exploratoria. Estudio patrocinado por la Vicaría de la Solidaridad del Arzobispado de Santiago y por UNELAM. Santiago: Oficina Regional para América Latina.

Lagos Humberto. 1988. Crisis de la esperanza. Religión y autoritarismo en Chile. Santiago: Presor y Lar.

Lagos, Humberto 1991. “Chile: ¿Legitimidad metasocial o afirmación del Dios de la Vida?”, en René Padilla (Compilador), De la marginación al compromiso. Los evangélicos y la política en América Latina. Buenos Aires: Florida.

Lalive d'Epinay, Christian. 2009. El refugio de las masas: estudio sociológico del protestantismo chileno. 2da. edición. Concepción: USACH y CEEP.

Lalive d'Epinay, Christian. 1968b. "La 'conquista' pentecostal en Chile. Elementos para su mejor comprensión". Mensajes 17 (170) Julio. Santiago.

Löwy, Michael. 1999. Guerra de dioses: religión y política en América Latina. México: Siglo XXI.

Maldonado Matías. 2012. Evangélicos y política en Chile, 1974-1986. El Consejo de Pastores y la Confraternidad Cristiana de Iglesias. Informe final para optar al grado de Licenciado en Historia. Universidad de Chile. Facultad de Filosofía y Humanidades. Departamento de Ciencias Históricas. Santiago.

Molina, Pilar. 1987. "La explosión protestante en Chile". El Mercurio, domingo 18 de octubre de 1987, Cuerpo D p. 2-3.

Moscovici, Serge. 1981/1996. Psicología de las minorías activas. Barcelona: Morata.

Ossa, Manuel. 1999. Iglesias evangélicas y derechos humanos en tiempos de dictadura. La Confraternidad Cristiana de Iglesias 1981-1989. Santiago: Fundación Konrad Adenauer - Centro Ecuménico Diego de Medellín.

Palma, Irma (ed) 1988. En tierra extraña. Itinerario del pueblo pentecostal chileno. Santiago: Amerinda.

Pope, Liston. 1942. Millhands and preachers: a study of Gastonia. Yale University Press.

Santa Ana, Julio. 1989. "Fundamentos de la paz: una reflexión teológica". En Hacia una Cultura de la Paz, Simón Espinosa (Compilador). Venezuela: Nueva Sociedad.

Sepúlveda, Juan. 1986. La Confraternidad Cristiana de Iglesias en el camino de la unidad. Santiago: Mecanografiado. 
Sepúlveda, Juan. 1990. "Bases éticas para la transición a la democracia desde la perspectiva evangélica". En CEDM Iglesia y transición en Chile. Santiago: Rehue.

Sepúlveda, Juan. 1993. "Reader's Digest: un informe 'muy especial' sobre el Consejo Mundial de Iglesias". Revista Evangelio y Sociedad 17: 15-18.

Sepúlveda, Juan. 1999. De peregrinos a ciudadanos. Breve historia del cristianismo evangélico en Chile. Santiago: Fundación Konrad Adenauer - Facultad Evangélica de Teología.

Sepúlveda, Juan. 2003. "La defensa de los derechos humanos como experiencia ecuménica". Persona y Sociedad 17 (3).

Sepúlveda, Juan. 2003. “El Principio Pentecostal. Reflexiones a partir de los orígenes del Pentecostalismo chileno". En Voces del Pentecostalismo Latinoamericano. Identidad, Teología e Historia. Daniel Chiquete y Luis Orellana (Editores). Concepción: RELEP.

Stoll, David. 1990. ¿América Latina se vuelve protestante? Las políticas del crecimiento evangélico. Quito. Ecuador: Editorial Abaya-Yala.

Tapia, Santiago. 1986. “Conversando con Monseñor Santiago Tapia, Vicario de la Solidaridad”. Evangelio y Sociedad 3: 4-8.

Tennekes, Hans. 1985. El movimiento pentecostal en la sociedad chilena. Iquique: Ciren- Universidad Libre de Ámsterdam.

Tillich, Paul. 1965. La era protestante. Buenos Aires: Paidós.

Valech, Sergio (ed.). 1991. Vicaría de la Solidaridad: Historia de su trabajo social. Santiago: Paulinas.

Vergara, Pilar 1985. Auge y caída del neoliberalismo en Chile. Santiago: FLACSO.

Vuscovic, Pedro. 1993. Pobreza y desigualdad en América Latina. México: UNAM.

Weber, Max. 2001. Ensayos sobre sociología de la religión, Tomo I. Madrid: Taurus.

Weingartner, Erich. 1988. “Detrás de la máscara. Los derechos humanos en Asia y América Latina. Un encuentro interregional". Ginebra y Quito: CMI- CLAI.

Willems, Emilio. 1967. Followers of the New Faith. Culture, Change and the Rise of Protestantism in Brazil and Chile. Nashville: Vanderbilt University Press.

Zañartu, Enrique. 1938. Hambre, miseria e ignorancia. Santiago: Ercilla.

\section{Revistas y diarios}

Análisis, 1986. Evangélicos: separando aguas con Pinochet. Semana del 2 al 8 de septiembre de 1986. Santiago. Evangelio y Sociedad. 1985, 1986 y 1987. Servicio Evangélico para el Desarrollo (SEPADE), Santiago.

Miguel Ángel Mansilla es investigador del Instituto de Estudios Internacionales (INTE) de la Universidad Arturo Prat; Sociólogo de la Universidad Arturo Prat y doctor en Antropología de la Universidad de Tarapacá (UTA) y Universidad Católica del Norte. En 2013 fue Profesor invitado de agosto a diciembre en el postgrado de Ciencias da Religiáo de la Universidade Metodista de Sao Paulo, Brasil. En 2012 hizo una pasantía posdoctoral en el Centre for Pentecostal and Charismatic Studies de la Universidad de Birmingham, Inglaterra. Autor del Libro: "La Cruz y la Esperanza. La cultura del pentecostalismo chileno en la primera mitad del siglo XX". Editorial MANDA-UNAMUNAP, México (Segunda Edición 2014).

E-mail: mansilla.miguel@gmail.com.

Juan Sepúlveda es licenciado en estudios teológicos en el Instituto Superior Evangélico de Estudios Teológicos, Buenos Aires, Argentina y doctor en la Facultad de Artes de la Universidad de Birmingham (GB). Es también director de planificación institucional del "Servicio Evangélico para el Desarrollo" y profesor del curso de Historia de las Iglesias en la Comunidad Teológica Evangélica de Chile. E-mail: juan.sepulveda@sepade.cl.

Luis Orellana Urtubia es licenciado en ciencias teológicas en la Universidad Bíblica Latinoamericana, San José, Costa Rica; Becario CONICYT y doctor ( en estudios americanos de la Universidad de Santiago de Chile. Además es investigador del Instituto de Estudios Internacionales (INTE) de la Universidad Arturo Prat.

E-mail: luis_ubl@yahoo.com. 
